\title{
Mutation screening of EXT1 and EXT2 by direct sequence analysis and MLPA in patients with multiple osteochondromas: splice site mutations and exonic deletions account for more than half of the mutations
}

Geraldine R Vink $^{*}{ }^{1}$, Stefan J White ${ }^{1}$, Strelicija Gabelic ${ }^{1}$, Pancras CW Hogendoorn ${ }^{2}$, Martijn H Breuning ${ }^{1}$ and Egbert Bakker ${ }^{1}$

${ }^{1}$ Center for Human and Clinical Genetics, Leiden University Medical Center, Leiden, The Netherlands; ${ }^{2}$ Department of Pathology, Leiden University Medical Center, Leiden, The Netherlands

Multiple osteochondromas (MO) is an autosomal dominant condition, caused by mutations in either the EXT1 or the EXT2 gene. The DNA of a cohort of 35 patients, clinically suspected to be affected with MO, was screened for mutations by a combination of direct sequence analysis and multiplex ligation-dependent probe amplification (MLPA). In this cohort, 26 pathogenic gene alterations were found (74\%). With sequence analysis mutations were detected in 22 patients $(63 \%)$. In total, 10 mutations were detected in the EXT1 and 12 in the EXT2 gene. The number of the splice site mutations detected was larger than expected from the literature. In addition, with the MLPA four deletions of one or more exons were found in this cohort. Two patients, of whom one had a negative family history, showed deletions of exon 1 of the EXT1 gene, which is possibly a deletion hot spot. In patients suspected to be affected by MO, we recommend a quantitative analysis such as MLPA, followed by direct sequence analysis for the screening of the EXT1 and EXT2 genes.

European Journal of Human Genetics (2005) 13, 470-474. doi:10.1038/sj.ejhg.5201343

Published online 8 December 2004

Keywords: osteochondromas; MLPA; mutation screening; EXT1; EXT2

\section{Introduction}

Multiple osteochondromas (MO), previously known as hereditary multiple exostoses, is an autosomal dominant condition characterized by the development of $\mathrm{MO}$ localized mainly in the juxtaepiphyseal region of long bones. ${ }^{1}$ Osteochondromas are rarely present at birth but appear and grow throughout childhood and into puberty.

*Correspondence: Dr GR Vink, Center for Human and Clinical Genetics, Leiden University Medical Center, Wassenaarseweg 72, 2333AL Leiden, The Netherlands. Tel: +31 71527 6082; Fax: + 3171527 1601; E-mail: g.r.vink@lumc.nl

Received 29 July 2004; revised 21 October 2004; accepted 22 October 2004
They vary greatly in number and size. Apart from the development of osteochondromas, MO is characterized by skeletal deformities and disproportionate short stature. Malignant transformation resulting in peripheral secondary chondrosarcomas is the most serious complication and occurs in $1-5 \%$ of EXT patients. ${ }^{2-4}$

$\mathrm{MO}$ is genetically heterogeneous and at present, two genes, EXT1 and EXT2 located on 8q24 and 11p11-p12, respectively, have been cloned. ${ }^{5-7}$ EXT1 has been shown to act as a tumour suppressor gene causative for the development of osteochondromas in hereditary cases. ${ }^{8} \mathrm{MO}$ are also seen in contiguous-gene syndromes mapped to chromosome 8q24.1 (Langer-Giedion syndrome) and 11p11-p12 
(proximal 11p syndrome). Sporadic osteochondromas are histopathologically indistinguishable from those seen in MO or in a contiguous-gene syndrome. ${ }^{1}$

Various methods for the mutation screening of the EXT1 and EXT2 genes have been described. Most published alternatives use indirect methods, like conformation sensitive gel electrophoresis (CSGE) ${ }^{9}$ and single-strand conformation polymorphism (SSCP), ${ }^{10,11}$ to detect sequence variations, and all ignore the intragenic rearrangements as a possible cause for MO. Multiplex ligationdependent probe amplification (MLPA) has recently been described as a quick and simple technique for the precise quantification of multiple sequences in a DNA sample. ${ }^{12}$ It has already successfully been applied to several genes and chromosomal locations where deletions and duplications are known to occur frequently. ${ }^{13,14}$ In a previous study, a group of patients with MO was tested with two-colour MLPA and five exonic deletions were detected. ${ }^{15}$ Some of these tested patients were part of a larger cohort of probands with MO. Here we describe the mutation screening of the EXT1 and EXT2 genes by a combination of direct sequence analysis and MLPA in a cohort of 35 patients, clinically suspected to be affected with MO. The aim was to determine the mutation spectrum and the frequency of exonic deletions and duplications in such a cohort.

\section{Materials and methods Patients}

EDTA blood samples of 35 index patients were obtained for DNA screening for mutations in the EXT1 and EXT2 genes. The phenotype of these patients was evaluated by clinical geneticists, paediatricians and internists and they were clinically diagnosed with MO. In total, 15 patients had a positive and 14 patients a negative family history. Of six patients the family history was unknown. In total, 28 patients originated from the Netherlands and seven from other countries within Europe.

Genomic DNA was purified from peripheral blood lymphocytes by salting out precipitation according to standard procedure. ${ }^{16}$

\section{Direct sequence analysis}

The PCR for the sequence analysis was performed with oligonucleotide primers specific for the coding exons of the EXT1 and EXT2 genes, extended with an M13-forward or reverse sequence. Exon 1 of EXT1 was split into six and exon 2 of EXT2 into two overlapping fragments. Primers were according to Wells et $a l^{17}$ for the fragments $1 \mathrm{c}, 1 \mathrm{e}, 1 \mathrm{f}$ and 2 until 10 of EXT1. For the primer sequence of the other fragments of EXT1 and all the primers of EXT2 see Table 1. PCR products were sequenced on an ABI 3730 DNA Analyzer (Applied Biosystems) using the BigDye Terminator Cycle Sequencing Ready Reaction Kit (Applied Biosystems). The raw sequence data were analysed using
SeqScape Software for comparative sequence analysis (Applied Biosystems). Detected mutations and unclassified variants (UV) were confirmed on a second independent DNA sample when available.

\section{Two-colour MLPA}

MLPA is a method for relative quantification of up to 40 different DNA sequences in a single reaction. The twocolour MLPA was performed as described previously. ${ }^{15}$ In short, in an one-tube format, combinations of two adjacently annealing oligonucleotide probes were hybridized and ligated. After ligation, the common ends of the probes served as a template for PCR amplification with one primer pair and due to the fluorescent labeling of the primer the resulting products could be separated according to size using capillary electrophoresis on the ABI 3700 (Applied Biosystems). Fragment data were analysed in GeneScan (Applied Biosystems). Peak heights of patient samples were compared with control probes and ratios were calculated for all exons using an Excel spreadsheet. Thresholds for deletions and duplications were set at 0.75 and 1.25 respectively, and all samples were tested at least twice.

\section{Results}

We screened the EXT1 and EXT2 genes of 35 index patients with clinically diagnosed MO for mutations. Analysis started with direct sequence analysis of all coding exons of EXT1 and EXT2. When no pathogenic mutation was detected MLPA was performed. Nucleotide numbering of the EXT1 and EXT2 genes was based on the sequences provided by Ahn et $a l^{5}$ and Wuyts et al, ${ }^{7}$ respectively, with base one corresponding to the first base of the initiation codon (Accession nr. EXT1: NT_023811.12 and EXT2: NT_009237.13).

With sequence analysis, pathogenic mutations were detected in 22 patients (63\%) and uv's were detected in four patients (11\%) (Table 2). In total, 10 pathogenic mutations and one uv were detected in the EXT1 gene. Three splice site, two frame shift, three stop and two missense mutations were found. The uv was a missense mutation in exon 2. This variant was detected in a patient with a positive family history. Segregation analysis was not possible in this family but the variant was not detected in a control panel of 100 chromosomes.

Mutations in the EXT2 gene were detected in 12 patients. Seven different splice site, one frame shift and three stop mutations were found. One splice site mutation was detected in two probands. Two missense mutations were considered to be uv's. One of these uv's was a silent mutation, which was detected in two probands, both with a negative family history. The other variant c.764T $>\mathrm{C}$ was also detected in the affected sister, father and paternal 
Table 1 Primers used to amplify exons

\begin{tabular}{|c|c|c|}
\hline $\begin{array}{l}\text { Amplified } \\
\text { exon per } \\
\text { gene }\end{array}$ & Nucleotide sequence & $\begin{array}{l}\text { Amplifiec } \\
\text { size }(b p)\end{array}$ \\
\hline 1a EXT1 & 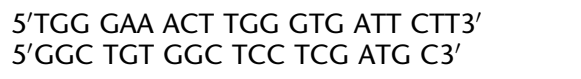 & 200 \\
\hline 1b EXT1 & $\begin{array}{l}5^{\prime} \text { CTC AGC TGG CTC TTG TCT CG } 3^{\prime} \\
5^{\prime} \text { GTT GGC ATC TCG CTT CTG C3 }\end{array}$ & 271 \\
\hline 1d EXT1 & $\begin{array}{l}5^{\prime} \text { GTT ACC AAA ACA TTC TAG CG } 3^{\prime} \\
5^{\prime} \text { CTT TGG CCA GCA TCG CCT GG3' }\end{array}$ & 303 \\
\hline 11 EXT1 & 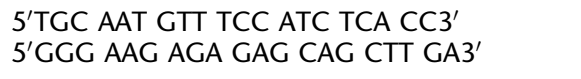 & 351 \\
\hline 2a EXT2 & $\begin{array}{l}\text { 5'TCA AGT GTC ATT TGC CAT CC } 3^{\prime} \\
\text { 5'TTT TGT TCT TTG GGT TGA AGC3' }\end{array}$ & 436 \\
\hline 2b EXT2 & $\begin{array}{l}\text { 5'GTG ATG TGC CGG TTG TTA GG3' } \\
\text { 5'CCT GAG GGC CAC TCA AGT AT3' }\end{array}$ & 436 \\
\hline 3 EXT2 & $\begin{array}{l}\text { 5'GGC TTG GGG ATC CTT GAT AG } 3^{\prime} \\
\text { 5'CAT GAA CAA AAT GAT CTT GAA CC } 3^{\prime}\end{array}$ & 277 \\
\hline 4 EXT2 & $\begin{array}{l}\text { 5'TTC CTG TTC CTC TCC ACA GT3' } \\
5^{\prime} \text { TTG ATG CCC ACC ACA CTA AA3' }\end{array}$ & 309 \\
\hline 5 EXT2 & $\begin{array}{l}\text { 5'TGG AGT GAA GAC TGG TAA GGA A3' } \\
\text { 5'TCG CTG GGC TCA ATT TTA AC3' }\end{array}$ & 420 \\
\hline 6 EXT2 & $\begin{array}{l}5^{\prime} \text { GGC GTC AAC CCT TGT AGA AA3' } \\
5^{\prime} \text { CAA TGA CCT GAG GAG ATT TTA TTT G3' }\end{array}$ & 349 \\
\hline 7 EXT2 & $\begin{array}{l}\text { 5'TGG GAT GTT GTT TCT GCT TG3' } \\
\text { 5'TAT CCA GTC AAG GCC ACC AT3' }\end{array}$ & 293 \\
\hline 8 EXT2 & $\begin{array}{l}\text { 5'TCC CAC TCT GTC TCG CTT G3' } \\
\text { 5'ACC CTC ACA GCT GGA CCA T3' }\end{array}$ & 269 \\
\hline 9 EXT2 & $\begin{array}{l}\text { 5'TGG GTC AGC CAT ATT GTT ACA G3' } \\
\text { 5'ATT TGG CCA TCC AAA ATT GA3' }\end{array}$ & 336 \\
\hline 10 EXT2 & $\begin{array}{l}\text { 5'GCC GTG GAT ACA AGC TGA TT3' } \\
\text { 5'ACG CAC ACC TTT TGG ACT CT3' }\end{array}$ & 452 \\
\hline 11 EXT2 & $\begin{array}{l}\text { 5'CAG CAC TGA ATG GTT GCT GT3' } \\
\text { 5'CCC TCT TGG CAG GTA TGA AA3' }\end{array}$ & 333 \\
\hline 12 EXT2 & $\begin{array}{l}\text { 5'GGC TAT GCT GCC CCT TAT TT3' } \\
\text { 5'ACA AGA ACT TCC TAG GCT CAG A3' }\end{array}$ & 316 \\
\hline 13 EXT2 & $\begin{array}{l}\text { 5'GTG TGG TGT CAC AAG CAT GA3' } \\
\text { 5'ACA GGC CTA AGG CAG GAA AT3' }\end{array}$ & 257 \\
\hline 14 EXT2 & $\begin{array}{l}\text { 5'CCC ATC CTT CTC ATT CTG CT3' } \\
\text { 5'GCT CGA GGT GCT TGG ATA TT3' }\end{array}$ & 420 \\
\hline
\end{tabular}

Annealing temperature for all exons is $55^{\circ} \mathrm{C}$, except for exon 10 of EXT2. For this exon the annealing temperature is $65^{\circ} \mathrm{C}$.

grandfather. Neither variant was found in 100 control chromosomes.

In nine patients $(26 \%)$, no possible pathogenic gene alteration was detected with sequence analysis. The DNA of these nine probands and the DNA of the four patients with an unclassified variant were further analysed with twocolour MLPA. Four deletions were detected (11\% of the total number of patients), three in the EXT1 and one in the EXT2 gene (Table 2). A deletion of exon 1 of the EXT1 gene was detected in two patients.

In total, 12 of the patients with a gene alteration had a positive family history (46\%), nine had a negative family history (35\%) and of five the family history was unknown (19\%). Three of the four patients with an exonic deletion had a positive family history.

\section{Discussion}

We have analysed 35 index patients, clinically affected with MO for the presence of mutations and exonic deletions in the EXT1 and EXT2 genes. This mutation screening was performed with direct sequence analysis and MLPA. Direct sequence analysis was chosen because of its very high mutation detection rate. This method, however, does not detect exonic deletions and duplications. To detect these quantitative gene alterations MLPA was used. This is a quick and simple technique that allows the rapid and precise quantification of multiple sequences. The twocolour approach was chosen, because it allows the rapid development of a set of probes. Especially in case of a rare disease, this approach is a good alternative to the cloning of probes.

After performing the sequence analysis and MLPA, 13 patients were found to have a mutation or a deletion in the EXT1 gene (37\%), and another 13 had an EXT2 mutation or deletion (37\%). In addition to these pathogenic mutations, uv's were detected in four patients, one in EXT1 and three in EXT2.

This mutation detection rate of $74 \%$ in a cohort of patients, clinically affected with MO is in accordance with Wuyts et al, ${ }^{18}$ who, on the basis of other literature, state that mutations in EXT1 and EXT2 are responsible for over $70 \%$ of the cases. In five of the index patients analysed, no possibly disease-causing mutation could be detected.

There are several plausible reasons as to why pathogenic mutations could not be detected in every patient. The promoter regions of the EXT1 and EXT2 genes were not examined for mutations. Furthermore, material of the index patients was sent to confirm the clinical diagnosis of MO with DNA-analysis. It is uncertain for us whether in all cases the phenotype of the patient fully matched the clinical picture of MO. In routine clinical practice MO can be confused with skeletal disorders affecting multiple bones, such as Olliers disease or metachondromatosis. Therefore, we recommend the phenotype as well as the skeletal radiographs to be evaluated by expert review before the initiation of mutation analysis. Also, the mutation could be missed in patients who are somatic mosaics. The 
Table 2 Gene alterations detected in the EXT1 and EXT2 genes by direct sequence analysis and MLPA

\begin{tabular}{|c|c|c|c|c|}
\hline & & Exon & Type of mutation & Family history \\
\hline \multicolumn{5}{|l|}{ EXT1 } \\
\hline c. $963-2 \mathrm{a}>\mathrm{g}$ & & 2 & Splice & Positive \\
\hline c. $1056+1 \mathrm{~g}>\mathrm{a}$ & & 2 & Splice & Positive \\
\hline c. $1018 \mathrm{C}>\mathrm{T}$ & p. R340C & 2 & Missense & Negative \\
\hline c. $1019 \mathrm{G}>\mathrm{A}$ & p. R340H & 2 & Missense & Negative \\
\hline c. $1160 \mathrm{~T}>\mathrm{A}$ & p. L387X & 3 & Stop & Positive \\
\hline c. $1225 \mathrm{delCA}$ & p. Q409fsX & 4 & Frame shift & Positive \\
\hline c. 1469 insC & p. L490fsX & 6 & Frame shift & Negative \\
\hline c. $1535-1 \mathrm{G}>\mathrm{T}$ & & 7 & Splice & Negative \\
\hline c. $1696 \mathrm{G}>\mathrm{T}$ & p. E566X & 8 & Stop & Unknown \\
\hline c. $1842 \mathrm{C}>\mathrm{T}$ & p. Q648X & 10 & Stop & Unknown \\
\hline c. -772-?_962+?del (del ex 1) & & 1 & Deletion & Positive \\
\hline c. $-772-? 962+$ ?del (del ex 1$)$ & & 1 & Deletion & Negative \\
\hline c. 963-?_3287+?del (del ex 2-11) & & $2-11$ & Deletion & Positive \\
\hline $1027 \mathrm{G}>\mathrm{T}$ & p. G343W & 2 & Unclassified variant & Positive \\
\hline \multicolumn{5}{|l|}{ EXT2 } \\
\hline c. 201 ins C & p. P67fsX & 2 & Frame shift & Unknown \\
\hline c. $536+1 \mathrm{~g}>\mathrm{a}$ & & 2 & Splice & Negative \\
\hline c. $544 \mathrm{C}>\mathrm{T}$ & p. R182X & 3 & Stop & Unknown \\
\hline c. $626+1 \mathrm{~g}>\mathrm{a}$ & & 3 & Splice & Negative \\
\hline c. $626+1 \mathrm{delg}$ & & 3 & Splice & Positive \\
\hline c. $659 \mathrm{G}>\mathrm{A}$ & p. W220X & 4 & Stop & Positive \\
\hline c. $743+1 \mathrm{~g}>\mathrm{a}$ & & 4 & Splice & Negative \\
\hline c. $743+1 \mathrm{~g}>\mathrm{t}$ & & 4 & Splice & Positive \\
\hline c. $1080-2 a>g$ & & 7 & Splice & Positive \\
\hline c. $1080-2 \mathrm{a}>\mathrm{g}$ & & 7 & Splice & Unknown \\
\hline c. $1112 \mathrm{C}>\mathrm{G}$ & p. S371X & 7 & Stop & Neqative \\
\hline c. $1173+1 \mathrm{~g}>\mathrm{a}$ & & 7 & Splice & Positive \\
\hline c. -30-10_441del (del ex 2) & & 2 & Deletion & Positive \\
\hline c. $519 \mathrm{G}>\overline{\mathrm{C}}$ & p. A173A & 2 & Unclassified variant & Negative \\
\hline c. $519 \mathrm{G}>\mathrm{C}$ & p. A173A & 2 & Unclassified variant & Negative \\
\hline c. $764 \mathrm{~T}>\mathrm{C}$ & p. L255P & 5 & Unclassified variant & Positive \\
\hline
\end{tabular}

mutation has to be present in at least $25 \%$ of the lymphocytes to be detected by direct sequence analysis. Another possibility is the existence of a third gene (EXT3) that is responsible for the clinical picture of MO. In previous literature, linkage analysis suggested that this gene could be located on the short arm of chromosome 19. ${ }^{19}$ This reported linkage however has never been observed by other groups, nor has a responsible gene at this locus been cloned. Lastly, positional changes like translocations, inversions or insertions that affect the structure of the gene and the function of the protein will not be detected by either sequence analysis or MLPA.

With the MLPA four deletions were detected in this cohort of 35 index patients. Thus, a significant amount of the mutations present in patients with MO consist of an exonic deletion. In this study exonic deletions seem to occur more often in EXT1 than in EXT2, but the numbers of deletions are too small to determine if this is significant. Noticeable, however, is that in two cases a deletion of exon 1 of the EXT1 gene was detected. This deletion was also detected in another DNA sample, originating from another laboratory. A common ancestor is unlikely, since all three patients originate from a different country, the Nether- lands, Spain and the United States and have different haplotypes. Besides, the deletion of one patient seems to have occurred de novo, since the family history is negative. Clustering of deletions in intron one is explainable by the large size of this intron. Further work needs to be carried out to determine the breakpoints and more patients need to be tested to define the full deletion spectrum.

Wuyts et al $^{18}$ stated that for European patients the fraction of mutations in EXT1 is slightly higher than that in EXT2. The mutations detected with sequence analysis in this cohort were evenly distributed between the EXT1 and EXT2 genes and, thus, in this cohort both genes seem to play an almost equal role in the occurrence of MO.

In the EXT1 gene, more than one-third of the mutations were detected in exon 2. Along with two splice site mutations, two different missense mutations were detected in this exon at amino-acid position R340. Clustering of variants in the amino acids G339 and R340 has been reported before. ${ }^{9,10,20}$ The crucial function of these amino acids for the EXT1 protein was confirmed by McCormick et $a l^{21}$ who showed that EXT1 constructs containing missense mutations G339D and R340C are completely inactive in vitro. 
With sequence analysis, no mutation was detected in exon 1 of the EXT1 gene, although exon 1 codes for more than $40 \%$ of the EXT1 protein. In the EXT2 gene, all mutations were detected in the exons $2,3,4$ and 7 . This uneven distribution is in accordance with Wuyts et al (2000). The carboxy terminal region of EXT2 contains fewer mutations than would be expected in a random distribution.

Striking is, that, compared with the literature $11,18,21,22$ we find a much larger proportion of splice site mutations. A total of $50 \%$ of the pathogenic mutations involve either a splice donor or a splice acceptor site. Especially in the EXT2 gene, the percentage of detected splice site mutations was high (67\% of the mutations found in EXT2). Some of the splice site mutations were described before, while others were not published in the literature or in a database. All of the newly detected splice site mutations involved the last nucleotide of the intron or the first of the exon in case of the splice acceptor site, and in case of the splice donor site the last nucleotide of the exon or the first of the intron. There were two exceptions, c.963-2a $>$ g in EXT1 and c.1080-2a $>$ g in EXT2. This last mutation was detected in two independent index patients. In the family of one of these index patients cosegregation of osteochondromas and this splice site mutation with the disease could be demonstrated. Using a splice prediction programme, all splice site mutations caused the loss of the original splice site (www.fruitfly.org).

Three different uv's were detected with sequence analysis. None of them was detected in 100 control chromosomes, so pathogenicity could not be excluded. The segregation analysis of c.764T $>C$ was suggestive for this variant to be disease causing.

In conclusion, we have found 26 gene alterations in 35 index patients who were clinically affected with MO. Four of the gene alterations were exonic deletions detected with MLPA. The number of splice site mutations was larger than expected from the literature. For the screening of the EXT1 and EXT2 genes we recommend a quantitative analysis such as MLPA followed by direct sequence analysis.

\section{References}

1 Bovee JVMG, Hogendoorn PCW: Multiple osteochondromas; In: Fletcher CDM, Unni KK, Mertens F (eds). World Health Organisation Classification of Tumours. Pathology and Genetics of Tumours of Soft Tissue and Bone. Lyon: IARC Press, 2002, pp 360-362.

2 Schmale GA, Conrad EU, Raskind WH: The natural history of hereditary multiple exostoses. J Bone Jt Surg Am 1994; 76: 986-992.

3 Wicklund LC, Pauli RM, Johnston D, Hecht JT: Natural history study of hereditary multiple exostoses. Am J Med Genet 1995; 55: $43-46$.
4 Bertoni F, Bacchini P, Hogendoorn PCW: Chondrosarcoma; In: Fletcher CDM, Unni KK, Mertens F (eds). World Health Organisation Classification of Tumours. Pathology and Genetics of Tumours of Soft Tissue and Bone. Lyon: IARC Press, 2002, pp 247-251.

5 Ahn J, Ludecke $\mathrm{H}$, Lindow $\mathrm{S}$ et al: Cloning of the putative tumor suppressor gene for hereditary multiple exostoses (EXT1). Nat Genet 1995; 11: 137-143.

6 Stickens D, Clines G, Burbee D et al: The EXT2 multiple exostoses gene defines a family of putative tumour suppressor genes. Nat Genet 1996; 14: 25-32.

7 Wuyts W, van Hul W, Wauters J et al: Positional cloning of a gene involved in hereditary multiple exostoses. Hum Mol Genet 1996; 5: $1547-1557$.

8 Bovee JVMG, Cleton-Jansen AM, Wuyts W et al: EXT-muntation analysis and loss of heterozygosity in sporadic and hereditary osteochondromas and secondary chondrosarcomas. Am J Hum Genet 1999; 65: 689-698.

9 Phillipe C, Porter DE, Emerton ME, Wells DE, Simpson AHRW, Monaco AP: Mutation screening of the EXT1 and EXT2 genes in patients with hereditary multiple exostoses. Am J Hum Genet 1997; 61: 520-528.

10 Wuyts W, Van Hul W, De Boulle K et al: Mutations in the EXT1 and EXT2 genes in hereditary multiple exostoses. Am J Hum Genet 1998; 62: 346-354.

11 Gigante M, Matera MG, Seripa D et al: EXT-mutation analysis in italian sporadic and hereditary osteochondromas. Int $J$ Cancer 2001; 95: 378-383.

12 Schouten JP, McElgunn CJ, Waaijer R, Zwijnenburg D, Diepvens F, Pals G: Relative quantification of 40 nucleic acid sequences by multiplex ligation-dependent probe amplification. Nucleic Acids Res 2002; 30: e57.

13 Hogervorst FB, Nederlof PM, Gille JJ et al: Large genomic deletions and duplications in the BRCA1 gene identified by a novel quantitative method. Cancer Res 2003; 63: $1449-1453$

14 Rooms L, Reyniers E, van Luijk R et al: Subtelomeric deletions detected in patients with idiopathic mental retardation using multiplex ligation-dependent probe amplification (MLPA). Hum Mutat 2004; 23: 17-21.

15 White SJ, Vink GR, Kriek M et al: Multi-colour MLPA; detectinggenomic rearrangements in EXT1 and EXT2 genes involved in hereditary multiple exostoses. Hum Mutat 2004; 24: 86-92.

16 Miller SA, Dykes DD, Polesky HF: A simple salting out procedure for extracting DNA from human nucleated cells. Nucleic Acids Res 1988; 16: 1215 .

17 Wells DE, Hill A, Lin X, Ahn J, Brown N, Wagner MJ: Identification of novel mutations in the human EXT1 tumor suppressor gene. Hum Genet 1997; 99: 612-615.

18 Wuyts W, van Hul W: Molecular basis of multiple exostoses: mutations in the EXT1 and EXT2 genes. Hum Mutat 2000; 15: 220-227.

19 Le Merrer M, Legeai-Mallet L, Jeannin PM et al: A gene for hereditary multiple exostoses maps to chromosome 19p. Hum Mol Genet 1994; 3: 717-722.

20 Raskind WH, Conrad EU, Matsushita $\mathrm{M}$ et al: Evaluation of locus heterogeneity and EXT1 mutations in 34 families with hereditary multiple exostoses. Hum Mutat 1998; 11: 231-239.

21 McCormick C, Leduc Y, Martindale D et al: The putative tumor suppressor EXT1 alters the expression of cell-surface heparan sulfate. Nat Genet 1998; 19: 158-161.

22 Francannet C, Cohen-Tanugi A, Le Merrer M, Munnich A Bonaventure J, Legeai-Mallet L: Genotype-phenotype correlation in hereditary multiple exostoses. J Med Genet 2001; 38: 430-434. 